\title{
A EXPANSÃO SEMÂNTICA DOS SIGNIFICADOS SOB A ÓTICA DA SEMIÓTICA SOCIAL
}

\author{
ZÁIRA BOMFANTE DOS SANTOS ${ }^{1}$ \\ ELIANE GONÇALVES DA COSTA ${ }^{2}$
}

Programa de Pós-Graduação em Ensino na Educação Básica

Universidade Federal do Espírito Santo - UFES

Centro Universitário Norte do Espírito Santo /CEUNES

Rodovia BR 101, km 60, Bairro Litorâneo, CEP 29932-540 - São Mateus - ES, Brasil

$\underline{\text { zaira.santos@ufes.br }}, \underline{\text { elianecoordena@gmail.com }}$

\begin{abstract}
Resumo. É crescente o interesse pelas pesquisas que investigam a multiplicidade de linguagem, modos ou semioses nos textos em circulação social, seja nos impressos, nas mídias audiovisuais, digitais ou não. Com o objetivo de propor uma breve discussão em torno da articulação dos modos semióticos na construção de significados dentro dos textos multimodais, este trabalho se ancora nos pressupostos teórico-metodológicos da Semiótica Social e da Multimodalidade preconizados por Hodge e Kress (1988); Kress e van Leeuwen (1996; 2006) e Kress (2010). Para consubstanciar a discussão, é realizada uma análise da orquestração dos significados em uma reportagem da revista Saúde, a partir das categorias analíticas da Gramática Sistêmico-Funcional e da Gramática do Design Visual.
\end{abstract}

Palavras-chave: Semiótica Social; Multimodalidade; Metafunção.

\begin{abstract}
It is increasing the interest in researchers that investigate the multiplicity of language, modes or semiosis in texts on social circulation. Aesthetic organization of several semiotic modes impregnates and makes contemporary texts mean. This work is grounded in the theoretical and methodological assumptions of Social Semiotics and Multimodality postulated by Hodge and Kress (1988); Kress and Van Leeuwen (1996, 2006) and Kress (2010). In order to substantiate the discussion, one analysis of the orchestration of meanings in a story of health magazine, from the analytical categories of Systemic Functional Grammar and the Grammar of Visual Design is done.
\end{abstract}

Keywords: Social Semiotic; Multimodality; Metafunction.

\footnotetext{
${ }^{1}$ Doutora em Estudos linguísticos pela UFMG e Professora adjunta do Departamento de Educação e Ciências Humanas - DECH/CEUNES/UFES e permanente no Programa de Pós-Graduação em Ensino na Educação Básica PPGEEB/UFES.

${ }^{2}$ Doutora em Estudos literários PUC/SP e professora colaboradora do Programa de Pós-Graduação em Ensino na Educação Básica PPGEEB/UFES.
} 


\section{INTRODUÇÃO}

O objetivo deste trabalho é situar as contribuições da Teoria Sociossemiótica da multimodalidade nos textos da esfera midiática de circulação social. A comunicação contemporânea tem passado por grandes transformações e as razões para tais transformações se assentam em uma vasta teia de mudanças sociais, econômicas, culturais e tecnológicas. A seleção de diferentes recursos semióticos realiza os textos multimodais caracterizando-os por um estilo de significados. Nestes parâmetros, situamos de forma sucinta as contribuições da Semiótica Social, a partir da apreciação de texto, mais precisamente em uma reportagem que versa sobre saúde, observamos a produção e a interrelação dos significados através de várias semioses. Assim, recorremos às contribuições (HALLIDAY, 1985; 2004); e aos trabalhos sobre Multimodalidade (KRESS, 2010; KRESS e VAN LEEUWEN, 2006), buscando observar a expansão semântica dos significados que vai delineando os discursos - as vozes do texto. A análise do texto revela um estilo de congruência dos modos semióticos na expansão de significados que buscam legitimar um discurso sobre saúde e como cuidar da saúde a partir da orquestração dos modos utilizados.

\section{SITUANDO A QUESTÃO}

Tentando lançar outro olhar sobre o design dos textos, este trabalho propõe uma reflexão sobre a orquestração dos modos semióticos verbais e visuais em um texto de popularização científica, mais especificamente da revista Saúde $^{3}$, que se propõe a divulgar e filtrar conhecimentos e informações da seara científica para o universo e linguagem dos leitores. Assim sendo, com o intuito de ampliar a concepção de texto, proponho observar a política de escolhas de modos semióticos para compreender como se dá o processo de orquestração - seleção/organização - da pluralidade de signos em diferentes modos, dentro de uma configuração, para formar um arranjo coerente no estabelecimento de relações com o leitor. Para tanto, utilizo a reportagem de capa por ser a capa do periódico um portador de texto que estabelece um contato direto e imediato com o leitor.

A motivação que levou a escolha do material a ser analisado está ancorada no aumento do espaço, seja no meio impresso ou no meio digital, que aborda o tema saúde bem como a multiplicidade de linguagem envolvida na constituição discursiva para a representação do tema. Expandindo esses pontos, a preocupação com a saúde e a corporeidade constitui-se em um processo interminável e em uma condição dos indivíduos na sociedade pós-moderna, além de informações nesse campo serem cada vez mais tratadas como uma popularização da ciência.

O processo de popularizar a ciência, segundo Motta-Roth (2009) deve ser visto como crucial para a sobrevivência da própria ciência (digamos, "erudita"), esta vista como um bem que deve ser produzido e cujo acesso deve ser democratizado em

\footnotetext{
${ }^{3}$ Reportagem selecionada da Revista Saúde, no 336, abril de 2011.
} 
sociedade. Textos de popularização científica são essenciais para a sobrevivência das áreas de conhecimento, uma vez que a sociedade, em grande medida, apoiará pesquisas em áreas construídas discursivamente pela mídia como relevantes. A popularização científica é considerada um processo complexo de recontextualização do conhecimento científico na mídia de massa para um público não especialista, a partir do qual o discurso científico é apropriado e rearticulado em meio a outros discursos para que a sociedade possa entender e participar desse processo que, ao mesmo tempo, democratiza e impulsiona as práticas científicas (MOTTA-ROTH, 2009, p. 136).

Assim, na rede textual da contemporaneidade, marcada pelas suas relações interdiscursivas, os discursos midiáticos - da publicidade ao jornalismo - fazem parecer não haver outro caminho para a grande maioria dos homens e mulheres que não o de se reconhecer, se relacionar consigo mesmo e com sua vida de acordo com os discursos, as imagens e os pressupostos veiculados pelos meios de comunicação:

\begin{abstract}
Nas mídias, aquilo que dá suporte às ilusões do eu são, sobretudo, as imagens do corpo, o corpo reificado, fetichizado, modelizado como ideal a ser atingido em consonância com o cumprimento da promessa de uma felicidade sem máculas. São, de fato, as representações nas mídias e publicidade que têm o mais profundo efeito sobre as experiências do corpo. São elas que nos levam a imaginar, diagramar, a fantasiar determinadas existências corporais, na forma de sonhar e desejar que propõem. (SANTAELLA, 2004, p. 125)
\end{abstract}

Considerando o primado pela saúde e o corpo atualmente, observaremos como se dá a orquestração dos modos semióticos e como eles se desdobram, tanto em meios de realização do discurso, como também de articulação discursiva a partir das ferramentas propostas pela abordagem sistêmico-funcional aplicada aos textos multimodais.

\title{
OS PRINCÍPIOS DA SEMIÓTICA SOCIAL
}

A Semiótica Social propõe o estudo do significado e da mensagem como ponto central, ao passo que a multimodalidade focaliza o estudo dos usos dos recursos semióticos e seus potenciais de significado a partir de diferentes origens e em diferentes contextos. Esses dois pontos, ou seja, o significado enquanto produção e o recurso enquanto representação juntam-se de forma motivada na comunicação multimodal, na qual "princípios semióticos em comum operam dentre e por entre os diferentes modos" e, portanto, torna-se "bem possível para a música codificar a ação ou para a imagem codificar a emoção" (KRESS e VAN LEEUWEN, 2001, p.2). Assim, os princípios semióticos perpassam os diferentes recursos disponíveis (sorriso, olhar, gestos, iluminação, cor, postura, palavras etc.) na vasta paisagem semiótica e são escolhidos como formas de representação pelos atores sociais de uma mensagem, por serem mais expressivos num dado momento da comunicação.

A linguagem multimodal é um fenômeno social, mais especificamente, uma forma de comportamento social que tem a função de comunicar algo. Para isso, opera dentro do sistema de interação humana permitindo-nos, portanto, a partir dela, investigar o relacionamento social. Dessa forma, quando escolhemos significados, somos orientados 
por aquilo que consideramos ser mais apto e plausível naquele momento e naquela cultura.

A rigor, a Semiótica Social tem foco no processo de significação, situando-o como parte da construção social. Para Hodge e Kress (1988, p. 261), a semiótica é "o estudo da semiose, dos processos e efeitos da produção, reprodução e circulação de significados em todas as formas, usados por todos os tipos de agentes da comunicação". Ela abarca "os significados socialmente construídos através de formas semióticas, textos semióticos e práticas semióticas de todos os tipos da sociedade humana em todos os períodos da história humana" (HODGE; KRESS, 1988, p. 261). A abordagem historicizada e crítica forma a base da Semiótica Social, cujo principal procedimento inclui a exploração e o mapeamento do significado, tendo em conta as dinâmicas culturais e ideológicas nas quais ele está imerso.

Nesses moldes, o uso da linguagem está conectado com os contextos de situação e de cultura nos quais ela opera. Esse significado potencial da comunicação, entendido a partir da máxima "poder significar", e equivalente a "poder fazer" quando traduzido pela linguagem, é investigado a partir de escolhas multimodais. É importante ressaltar que os significados com que operamos em uma determinada interação, sejam eles palavras, gestos ou olhares (ou qualquer outro recurso semiótico), são conteúdos políticos, na medida em que são formas que se encontram organizadas por nossos relacionamentos em grupos sociais e culturais.

Essa abordagem enfatiza o conceito de signo na sua produção, formas de articulação e interpretação. Com novos paradigmas, a Semiótica Social trabalha com a discussão de princípios semióticos amplos, dentre os quais destacamos: 1) a noção de escolha do sistema de linguagem; 2) as configurações de significado a partir do contexto; e 3) as funções semióticas da linguagem segundo a Linguística Sistêmico-Funcional: ideacional, interpessoal e textual.

\section{AS BASES SISTÊMICOS-FUNCIONAIS NA TEORIA SOCIOSSEMIÓTICA}

A unidade central da semiótica é o signo, a fusão de forma e significado. O signo existe em todos os modos e precisa ser considerado pelas suas contribuições ao significado. A gênese dos signos repousa nas ações sociais e, para tanto, os signos são criados ao invés de usados. O foco na criação do signo é um dos traços que distingue a perspectiva da Semiótica Social de outras formas de semióticas. Na perspectiva sociossemiótica de realização do significado, os indivíduos com suas histórias sociais, moldados socialmente, situados em ambientes sociais e utilizando fontes social e culturalmente criadas, são agentes e produtores na produção de signos e na comunicação.

A teoria sociossemiótica adota a perspectiva de Halliday (1985) e sua concepção metafuncional da linguagem propondo agregar algumas suposições fundamentais: (i) os signos são sempre criados em interação social; (ii) são motivados; (iii) não possuem relações arbitrárias de significados e forma; (iv) a relação motivada de uma forma e um significado são baseadas no interesse dos produtores do signo em uma interação social em que se tornam partes das fontes semióticas de uma cultura. Outrossim, a aptidão nesse 
processo significa que uma determinada forma possui os requisitos para ser a portadora de significado.

O principal objetivo da abordagem sistêmico-funcional é dar conta das formas em que a linguagem é utilizada na interação social para construir significados. A premissa para as investigações no curso dessa abordagem é que os significados realizados pelas escolhas linguísticas derivam da natureza das interações sociais que a linguagem é usada para codificar. De modo a dar conta da natureza dos usos da linguagem, Halliday e Matthiessen (2004) propõem a decomposição da língua em vários estratos relacionados entre si. A visão estratificada da língua configura-se como um propósito de se analisar a linguagem em vários planos: o plano de expressão, composto pela fonologia/grafologia; o plano de conteúdo, composto pela lexicogramática e pela semântica-discursiva; e o plano do contexto, composto pelos contextos de situação e cultura. A relação entre esses estratos é denominada de realização. Uma representação desses estratos é mostrada no quadro a seguir:

\begin{tabular}{ll}
\hline LINGUAGEM \\
\hline ESTRATO DE CONTEÚDO & SEMÂNTICO DISCURSIVO \\
& Relações discursivas (parágrafo e texto) \\
& Lexicogramática \\
& Orações complexas \\
& Oração \\
& Grupo de palavras \\
& Palavras \\
& (Sistema baseado metafuncionalmente)
\end{tabular}

A abordagem sistêmico-funcional está centrada na descrição e no uso da linguagem baseada em sistemas (experiencial, lógico, interpessoal e textual) para análise linguística. A natureza da abordagem sistêmica que opera no estrato do conteúdo e de expressão da linguagem parece ser diferente. É possível formular o sistema discursivo e lexicogramatical, considerando que possuem orientações metafuncionais distintas. $\mathrm{Na}$ perspectiva multimodal, o estrato de expressão tem sido considerado em seus aspectos tipográficos (fonte) na veiculação de significados ideacionais, interpessoais e textuais, bem como os aspectos fonológicos (proeminência de partes do texto através da tonicidade, organização rítmica das unidades de informação, padrões de entonação para questões, afirmações, comandos etc.)

Os textos multimodais integram seleções de diferentes recursos semióticos em sua organização. São compreendidos como produtos compostos de efeitos combinados de todos os recursos usados para serem criados e interpretados. Considerando as diversas 
semioses que compreendem os textos contemporâneos na constituição de um discurso, o sistema visual e o linguístico interagem num processo de integração e também podem diferir. No que se refere à estratificação do plano visual nos estratos de conteúdo e de expressão, há um modelo de extensão proposto por O’Toole:

\begin{tabular}{ll}
\hline VISUAL \\
\hline ESTRATO DE CONTEÚDO & SEMÂNTICO DISCURSIVO \\
& Relações intervisuais \\
& Gramática \\
& Cena \\
& Episódio \\
& Figura \\
& Parte \\
& (sistema baseado metafuncionalmente) \\
\end{tabular}

ESTRATO DE ESPRESSÃO Gráficos

Quadro 2: Estrutura Sistêmico-Funcional do visual (baseado em O'Toole, 1994)

Dada a multiplicidade de semioses presentes nos textos contemporâneos, sejam impressos ou digitais, eles são marcados pelo princípio de integração de recursos. Um sistema de recursos semióticos é um sistema de formas semióticas que podemos usar com a finalidade de produzir textos. Tais formas desempenham funções específicas nos textos em que são empregadas.

\section{DA CONCEPÇÃO DE MODO A ORQUESTRAÇÃO MULTIMODAL}

O mundo é textualizado e, cada vez mais, dialogamos com inúmeras interfaces semióticas no processo de representação e comunicação. Os modos são compreendidos como um recurso social e culturalmente moldado na produção de significados. Segundo Kress (2010, p. 81) são produtos do trabalho social e cultural, tendo significados em seus ambientes de produção como imagem, escrita, layout, cores, tipografia, música, gesto, fala, etc. Nesses termos, se todos os modos são usados para produzir significados, colocase em questão se eles são meramente um tipo de duplicação de significados já realizados na fala ou escrita - ilustração ou ornamentação - ou se são formas distintas, com significados distintos.

Os modos semióticos oferecem diferentes potencialidades na produção de significados, exercendo um efeito fundamental nas escolhas em uma instância específica de comunicação. Na perspectiva sociossemiótica de modo, é dada a mesma ênfase na 
materialidade do modo e no trabalho cultural desse material, dado que a cultura seleciona a materialidade dos modos. Em outros termos, as sociedades selecionam diferentemente e constantemente remodelam os recursos culturais/semióticos de modo. As sociedades têm preferências modais: um modo é usado para um propósito para um determinado agrupamento social e outros modos para outros propósitos.

Na perspectiva socialmente orientada, o modo é o que uma comunidade considera modo e utiliza em suas práticas sociais. Se há uma comunidade que usa recursos, por exemplo, fonte, layout, cor, com uma regularidade, consistência e suposições compartilhadas, esses recursos são modos para este grupo. Nesta via, os significados são acordados socialmente e específicos cultural e socialmente. A implementação e instanciação de vários modos simultaneamente possibilitam cada vez mais arranjos/disposições textuais marcados por uma linguagem coreografada.

Diversos gêneros discursivos, como os anúncios publicitários, os manuais de instrução, os hipertextos, as reportagens, as charges, as tiras, o livro didático, as capas de revistas, que estão por toda parte, possuem algo mais do que textos escritos (linguagem verbal) ou imagens, possuem multimodalidade. Conforme Descardeci (2002, p. 20),

(q)ualquer que seja o texto escrito, ele é multi-modal, isto é, composto por mais de um modo de representação. Em uma página, além do código escrito, outras formas de representação como a diagramação da página (layout), a cor e a qualidade do papel, o formato e a cor (ou cores) das letras, a formatação do parágrafo, etc. interferem na mensagem a ser comunicada. Decorre desse postulado teórico que nenhum sinal ou código pode ser entendido ou estudado com sucesso em isolamento, uma vez que se complementam na composição da mensagem.

Nesses parâmetros, Kress e van Leeuwen (2006, p. 2) sinalizam que os significados podem ser realizados na linguagem visual e na linguagem escrita. Coincidem em partes, algumas podem ser expressas, 'ditas', apenas visualmente e outras apenas verbalmente. O propósito da extensão é incluir os sistemas em que imagem se materializa em uma análise sistêmico-funcional multimodal discursiva. $\mathrm{O}$ estrato de expressão no plano visual é projetado de forma paralela ao estrato de expressão na linguagem. A natureza da organização da linguagem verbal e visual em estratos aponta para a organização metafuncional baseadas em sistemas de produção de significados. Esses significados são fontes para construção/representação de conteúdo - significados ideacionais; fontes para interação negociar as relações - significados interpessoais; fontes para organização textual - significados textuais. A perspectiva da análise sistêmico-funcional multimodal aborda a intersemiose entre os planos visual e verbal. Segundo Lemke

[...] um sinal de veículo material que elaboramos não pode ser construído apenas de acordo com um sistema semiótico. A escrita é tanto uma semiótica visual, como a linguística; discurso codifica a informação não linguística (chamado paralinguística) sobre os corpos, 
origens sociais e estados emocionais, bem como significados linguisticamente codificados. ${ }^{4}$ (LEMKE, 2011, p. 141)

Nesses propósitos, Lemke pontua que o resultado da semiose multimodal é multiplicativo na expansão de significados. Ao usar o termo efeito multiplicativo, o autor busca apreender a maneira como diferentes modalidades semióticas se co-contextualizam de forma que não são previsíveis na base de diferentes fontes semióticas, não podendo ser mais vistas como modalidades separadas.

\section{A ORQUESTRAÇÃO MULTIMODAL EM TEXTO IMPRESSO SOBRE SAÚDE}

É ponto pacífico na contemporaneidade a preocupação com a saúde, cuidar do bem-estar físico e da forma. Dada essa prática social, o número de reportagens sobre saúde, beleza e boa forma triplicou. Nas revistas contemporâneas, os "especialistas" dissertam sobre saúde, cuidados com o corpo em diferentes abordagens. Procurando observar as semioses utilizadas e como são orquestradas, proponho ilustrar como os campos de significados são criados intersemioticamente através do visual e o verbal em uma reportagem cujo escopo é a necessidade de manter-se no peso e emagrecer. Nessa reportagem, a revista deflagra a campanha Emagrece com o intuito de frear a epidemia da obesidade que tem se tornando um problema de saúde pública.

Escolhemos a reportagem de capa, visto que a capa se constitui uma das mais importantes propagandas da revista: o título da revista, os tons, as cores, as imagens servem para posicionar os leitores favoravelmente ao conteúdo da revista. As capas são produzidas com o objetivo de o leitor apreciar o conteúdo do periódico além de atingir fins comerciais junto ao seu público-alvo, divulgando as características, promovendo "informações" e qualidades inerentes ao produto ou serviço, para que, assim, o leitor/consumidor faça suas escolhas de acordo com suas necessidades e/ou desejos.

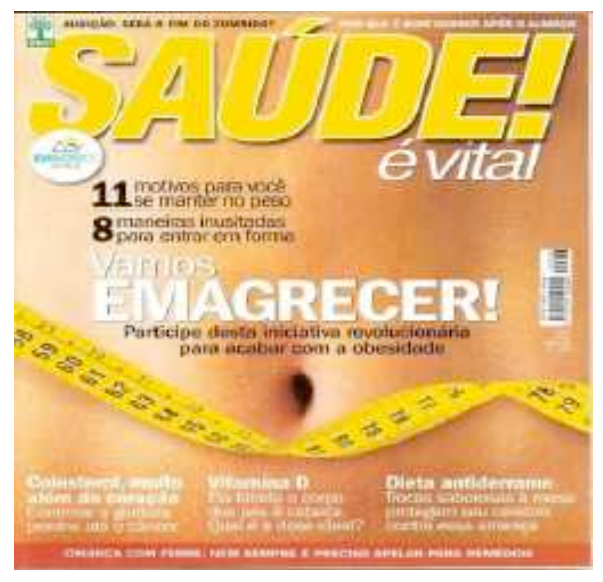

Figura 1 - Capa da Revista Saúde

\footnotetext{
${ }^{4}$ Tradução de: You cannot make a material sign-vehicle that can only be construed according to one semiotic system. Writing is as much a visual semiotic as a linguistic one; speech encodes non-linguistic (and so called paralinguistic) information about bodies, social origins, and emotional states as well as linguistically coded meanings.
} 
Nessa capa são elencados para o leitor 11 motivos para manter-se no peso e 8 maneiras para entrar em forma. Os aspectos visuais expõem a imagem da plena forma da região abdominal do corpo humano, destacando os atributos barriga sarada e pele uniforme, sendo acompanhados por uma fita métrica que contorna a região abdominal, convergindo para a ideia expressa no plano verbal da ação de emagrecer. A imagem ocupa o primeiro plano do espaço, sendo marcada por uma estrutura conceitual analítica que destaca os atributos do portador - a plena forma da região abdominal, barriga sarada e uma pele uniforme e sendo retratada a partir de um ponto de vista escolhido pelo produtor da imagem e imposto aos observadores. Essas configurações acentuam, nas palavras de Figueiredo (2009, p. 749), "um papel pedagógico de conhecimento para controle corporal, explicitando técnicas de autodisciplina".

As imagens são retratadas a partir de um ponto de vista escolhido pelo produtor e imposto aos observadores. Para Kress e Van Leeuwen (1996, p. 135), a seleção do tamanho do enquadramento e do ângulo, 'o ponto de vista', implica a possibilidade de expressar atitudes subjetivas em relação aos participantes representados, as quais podem ser socialmente determinadas. As imagens em questão representam possibilidades de atitudes determinadas socialmente, considerando os objetivos da reportagem e o que está arraigado na nossa prática social: manter o bem-estar e as medidas adequadas - boa forma - diante da necessidade de conter a obesidade. Quanto ao ângulo das imagens, ele é frontal, buscando o máximo envolvimento com o leitor. Em relação ao uso da tipografia e das cores, o peso da tipografia e a saliência conferidos no nome da revista e na informação "Vamos emagrecer" sintetizam as principais ideias do plano verbal que se reiteram no plano visual por meio da imagem abdominal e da fita métrica. Apoiando-nos em Sabat (2003), as imagens produzem conceitos ou pré-conceitos, formas de ensinar as coisas do mundo, formas de pensar e agir e se relacionar no e com o mundo. Nesse sentido, as imagens veiculadas representam um conceito de saúde e bem-estar ligado a um corpo esguio, sarado e uniforme.

Considerando os aspectos composicionais da capa, os itens visuais encontram-se conectados através de vetores - reiteração das cores amarela, preto e branca - que criam harmonia e coerência no espaço. O peso da tipografia conferido ao nome da revista, aos números 8 e 11 e na chamada Vamos Emagrecer sintetiza as principais ideias do plano verbal que se reiteram no plano visual através da imagem abdominal e da fita métrica. Assim, há integração textual aos itens visuais que se complementam na construção da unidade textual.

No interior da revista, a reportagem é composta por duas partes, sendo a primeira uma enumeração de 11 motivos para se manter no peso e na segunda parte 8 maneiras eficazes para o leitor emagrecer. $\mathrm{Na}$ abertura da reportagem, é realizado um trabalho no layout da página cuja tipografia confere peso a algumas informações, atraindo a atenção do leitor para um espaço composicionalmente marcado por molduras de uma balança que metaforicamente fixam o peso certo para o leitor, a partir da troca de informações: 


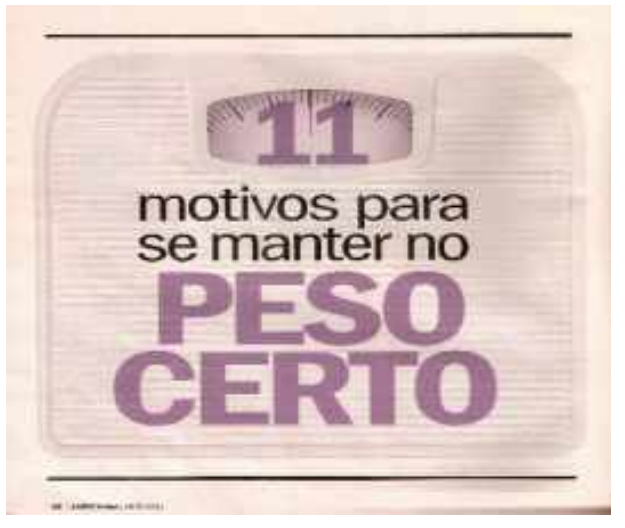

Figura 2 - aspectos tipográficos

A reportagem na sua totalidade perfaz 10 páginas marcadas por material visual em todas. Todo texto que compõe a reportagem é enumerado - segmentado - e o conteúdo visual segue o conteúdo verbal priorizado em cada segmento. Os itens visuais se distribuem dentro de estruturas conceituais:

\begin{tabular}{|rcc|}
\hline & \multicolumn{3}{c|}{ Significados representacionais no visual } \\
\hline 0 & 13 & 0 \\
\hline narrativo & conceitual analítico & conceitual simbólico conceitual classificacional \\
\hline
\end{tabular}

\section{Quadro 3 - Síntese dos significados visuais}

As informações do quadro demonstram que os itens visuais são dispostos dentro de estruturas conceituais analíticas - o material visual é colocado como um item de apreciação/explicativo e marcados por seus atributos possessivos. Essa disposição visa a identificar e conceituar elementos que se co-contextualizam no plano verbal, trazendo um paralelismo das informações em diferentes planos semióticos.
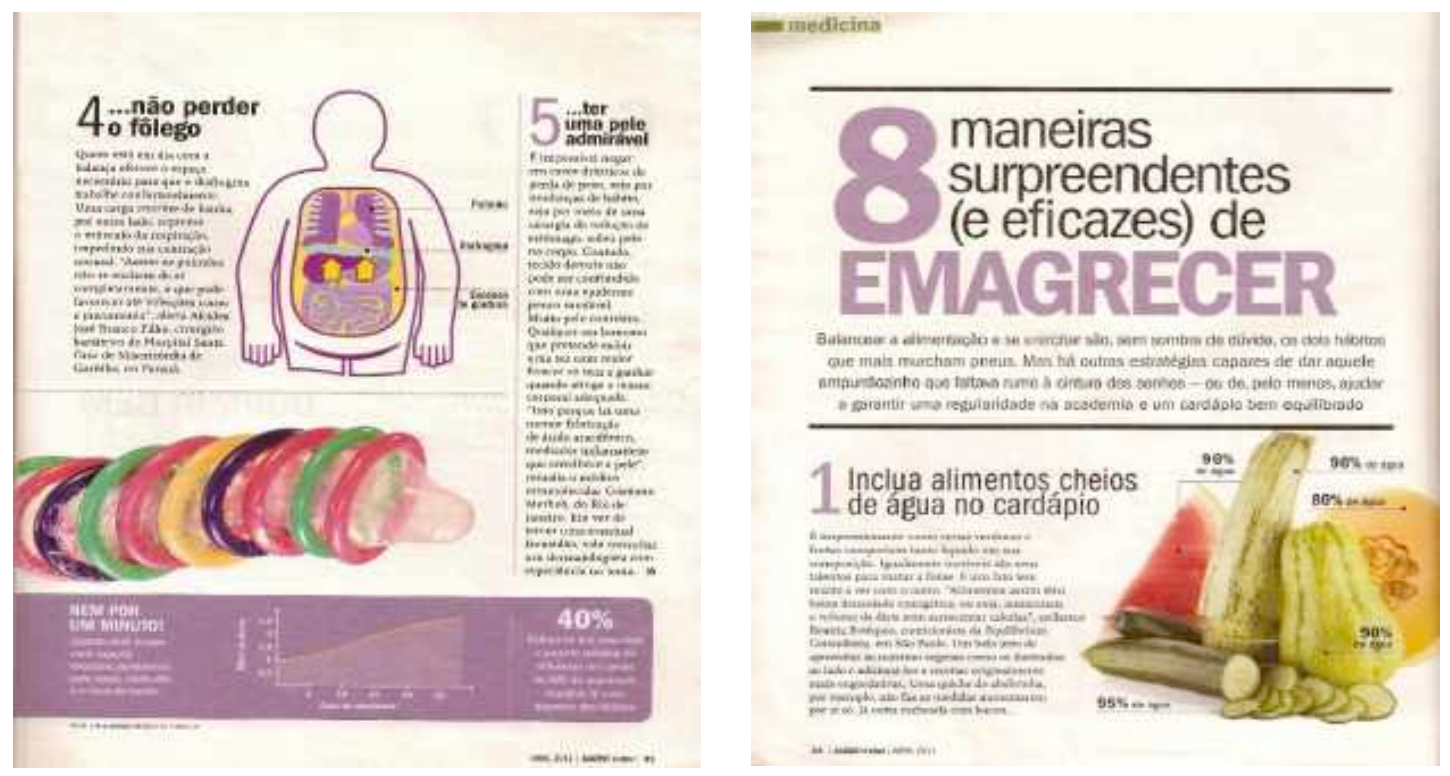

Figura 3 - estruturas conceituais 
As estruturas conceituais marcadas por processos classificacionais visam a classificar alimentos e descrever maneiras para o leitor de como se sentir bem, convergindo para uma similaridade das informações compartilhadas no plano verbal:

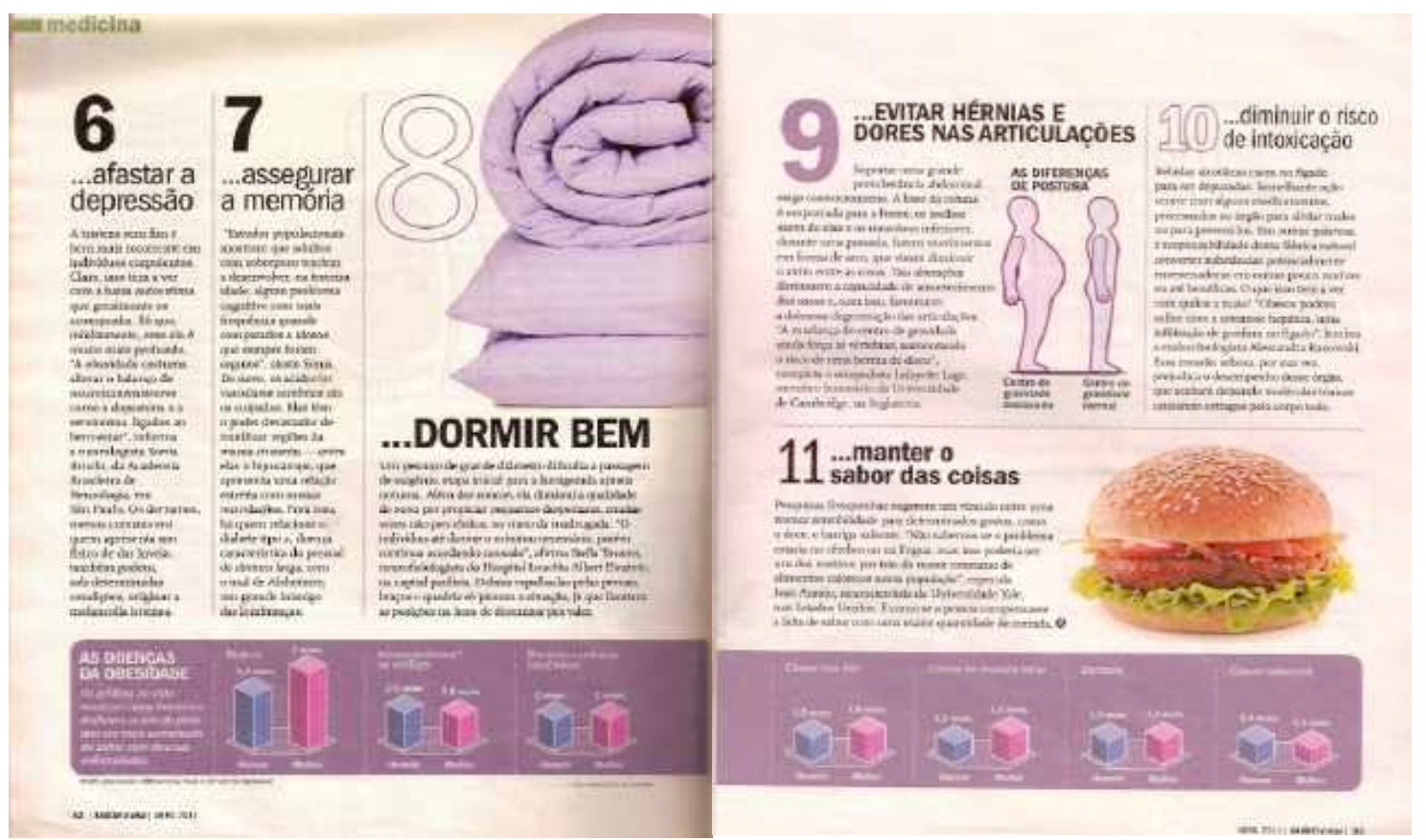

Figura 4 - Aspectos representacionais II

Observa-se que na parte inferior da página, figura 4, é trazida uma série de informações sobre gastos com tratamentos de pacientes obesos, as doenças da obesidade e as gerações brasileiras que já enfrentam problemas com excesso de gordura. Essas informações são sintetizadas em gráficos na forma de dados quantitativos e temporais, o que configura a presença de estrutura analítica espaço-temporal. Os gráficos estabelecem uma conjunção de estruturas analíticas e uma linha do tempo para análises comparativas. Segundo Kress e van Leeuwen (2006), as barras que traduzem os dados informativos criam processos dinâmicos, que podem ser traduzidos em ações como cresce, diminui, aumenta no que pode resultar em uma estrutura quase narrativa.

A conjunção dessas variadas formas de informações contribui para explorar a argumentatividade do texto, trazendo dados numéricos que reforçam as ideias principais da reportagem no lançamento de uma campanha contra obesidade. Todavia, nota-se que a saliência dada a algumas imagens e itens verbais (Saúde, 11 motivos para se manter no peso certo, 8 maneiras surpreendentes e eficazes de emagrecer) por meio do espaço maior, cores e brilho, capta nossa atenção além de realçar e deixar essas informações mais próximas da nossa apreciação. Logo, esses aspectos contribuem para a articulação do que está no plano representacional como algo mais próximo, no plano interacional, ao alcance do conhecimento do leitor.

$\mathrm{Na}$ arquitetura textual, nota-se um princípio de integração de significados no texto, conferindo uma coerência e ordenação entre os elementos. A visualização da composição espacial nos possibilita julgar o peso de vários elementos a partir de relevos: saliência. $\mathrm{O}$ resultado dessa articulação não é objetivamente mensurável, mas resulta da interação complexa entre vários fatores: tamanho, contraste de cor, nitidez de foco, contraste tonal 
(áreas com alto contraste, por exemplo, as fronteiras entre o preto e branco e o lilás, tem grande saliência), peso, criam uma importância entre os elementos, selecionando os mais importantes, os que depreendem mais atenção do leitor e guiam o percurso da leitura.

Buscando observar como se dá a orquestração dos significados no plano verbal, nota-se que as informações são trazidas dentro de uma tessitura marcadas por processos (verbos) materiais, cujo objetivo é sintetizar as ações dos participantes em seus aspectos do fazer/acontecer na ação desejada de emagrecimento. Os processos buscam revelar quais participantes e ações corroboram ou comprometem a manutenção da saúde em equilíbrio:

[...] Altas taxas de gordura corporal [ator] contribuem [processo material] para o surgimento do diabete tipo 2, [circunstância] uma enfermidade responsável por, entre outras coisas, minar [processo material] os vasos sanguíneos [meta], inclusive os que irrigam os olhos.

[...] A obesidade [ator] costuma alterar [processo material] o balanço de neurotransmissores como a dopamina e a serotonina, [meta] ligadas ao bem-estar.

São recorrentes os processos relacionais que buscam descrever/identificar os participantes, pontuar seus atributos, na construção dos fios argumentativos do texto e corroboram para a coesão semântica entre os elementos visuais e verbais no texto, estabelecendo, assim, uma intersemiose:

[...] Balancear a alimentação e se exercitar [característica] são, [processo relacional identificativo] sem sombra de dúvida, os dois hábitos que mais murcham pneus. [valor]

[...] O assunto [portador] ainda é [processo relacional atributivo] polêmico [atributo], porém acredita-se que ela seja benéfica também nesse quesito por auxiliar o trabalho do cálcio, nutriente com potencial para esvaziar os adipócitos, células que armazenam a gordura do corpo.

[...] Quem [portador] está [processo relacional circunstancial] em dia com a balança [atributo circunstancial] oferece o espaço necessário para que o diafragma trabalhe confortavelmente.

A configuração desses processos nos recortes constrói relações abstratas de classe e identidade e constitui os elementos que formam as figuras no domínio experiencial. Esses recortes, no domínio relacional, revelam que a classificação e a definição são subsídios argumentativos imprescindíveis para a construção das entidades representadas no evento. Isso mostra que a recorrência desse uso de experiência é um recurso valioso para a configuração da realidade construída. Os atributos nesses recortes buscam ratificar, em sua essência, uma configuração particular em torno da representação dos participantes.

A inserção de vozes no texto é comum para expressar conclusões, expectativas, especulações e outras informações. Dessas vozes, as mais recorrentes são as da comunidade midiática, com predominância da voz do jornalista, representada por meio do discurso indireto livre e pelo discurso indireto e direto de especialistas ligados ao 
tópico discutido. As vozes dos especialistas vão se alternando e sendo trazidas por processos verbais sob a forma de citação. Os processos são utilizados para exprimir ações verbais dos processos de dizer em torno dos experts, dando maior credibilidade à informação compartilhada com o leitor. Diversos processos verbais são usados para representar a locução dos participantes: prescreve; informa; salienta.

Os excertos mostram o que é comum nesses dizeres sob a perspectiva discursiva:

[...] "A situação é alarmante. Até mesmo os países desenvolvidos não conseguirão lidar com os custos desse fenômeno caso seu crescimento continue no ritmo atual", avisa [processo verbal] o endocrinologista carioca Walmir Coutinho, [dizente] da Associação Brasileira para o Estudo da Obesidade e da Síndrome Metabólica (Abeso). "É necessário mudar políticas, comportamentos e investir em atitudes voltadas para um estilo de vida mais saudável," prescreve. [processo verbal]

[...]A hipertensão, típica em pacientes com peso elevado, propicia as complicações na retina", II informa [processo verbal] Walmir Coutinho, da Abeso. [dizente]

[...] "Nesse estado, também sobem os níveis de cortisol, hormônio que ajuda a estocar gordura no organismo," salienta [processo verbal] Alessandra Rascovki, endocrinologista da Sbem. [dizente]

A rigor, as escolhas dos processos materiais, relacionais e verbais pontuam a dinâmica das ações dos participantes e os colocam, de maneira geral, para melhor esclarecimento do leitor, em dois polos: os que cooperam/são eficientes no equilíbrio da saúde e aqueles que se colocam como risco ou uma potencial ameaça, sendo o escopo dessas informações endossadas pela voz do especialista da área para aferir credibilidade às informações. $\mathrm{O}$ jogo de vozes de especialistas no decorrer da reportagem acentua $\mathrm{o}$ entremeamento de fronteiras entre o campo erudito (universo científico) e o campo popular e o de massa. A presença de especialistas nas publicações especializadas sobre saúde cumpre o papel de filtrar informações e conhecimentos da seara científica para o universo e linguagem dos leitores.

Dentro das construções linguísticas, é recorrente o uso de atos de fala ${ }^{5}$ objetivando a troca de conhecimento/informações, como também atos de fala de demanda, solicitando uma ação do potencial leitor. A reportagem é organizada em tópicos cujos títulos se configuram em um comando de forma explícita. Os atos de fala de dar informações perduram nos textos, buscando objetivar uma troca de conhecimento/informações, enquanto os atos de fala de demanda, mediante perguntas e comandos, interpelam o leitor. Neste cenário, as estruturas imperativas se colocam como itens a serem seguidos, requerendo uma ação do leitor a partir do compartilhamento da informação que pressupõe eficácia nas maneiras de garantir bem-estar e saúde:

\footnotetext{
5 O termo atos de fala, dentro da perspectiva sociossemiótica da linguagem refere aos diferentes papeis de fala que lançamos mão no processo de interação. Os papéis de fala mais fundamentais são: dar e demandar, em ambos o falante dá alguma coisa ao ouvinte (informação) ou requer algo. Essas categorias envolvem noções complexas em que "dar" significa convidar a receber e demandar convidar a dar. O falante não só faz algo para si como também requer algo do ouvinte". Outra distinção básica entre dar e demandar se relaciona com a natureza do que está sendo trocado: bens e serviços ou informação. Essas duas variáveis definem as quatro funções discursivas primárias: oferta, comando, declaração e pergunta.
} 
Dormir bem

Complemente a dieta com temperos picantes e alimentos roxos

Acerte a frequência dos exercícios físicos

Estabeleça um padrão de sono

Varie o ritmo

Distribua os exercícios na maior quantidade de dias possível...

Malhe o músculo da respiração

A interação no decorrer do texto é configurada lexicogramaticalmente por papéis de fala que requerem trocas de conhecimento e trocas de atividade objetivando um posicionamento do leitor diante das ideias veiculadas. Na reportagem, ainda fica evidente a presença da quase-interação mediada. Asinformações disponibilizadas atingem ambientes e espaços ilimitados, com receptores em números indefinidos, e que servem de ponte entre o conhecimento técnico e científico e o público leitor.

As escolhas realizadas nos planos representacional, interativo e composicional revelam a utilização de diversos modos semióticos simultaneamente, em conjunto modal, com uma função específica para a produção de uma mensagem. A possibilidade de escolha assentada no design revela, dentro do periódico, os propósitos da instância produtora em destacar a necessidade de se adquirir e manter a prática de cuidado com $o$ corpo e preservar os seus atributos, tanto no plano verbal, quanto no visual. Essa prática, reforçada, também, por valores culturais, explicita o estilo na construção do texto, o qual se implementa, segundo Kress (2010, p. 28), pelas instanciações de escolhas de diversos tipos que refletem o interesse do produtor no que considera relevante e adequado para $o$ seu público, como a própria instância produtora visualiza: indivíduos que valorizam o bem-estar/corpo saudável e a forma física.

Em aspectos gerais, a revista Saúde explora os modos semânticos verbais e visuais na constituição do texto. Contudo, as imagens são trazidas para representar em tom descritivo o que está contemplado no plano verbal, imagens conceituais que se articulam com o texto como síntese de informações. Os diversos modos semióticos vão tecendo o texto e construindo uma harmonia e paralelismo entre os planos verbal e visual. A produção de significados aponta para uma realidade aprendida na práxis do dia a dia, uma sociedade engajada nas atividades orientadas ao cuidado com a saúde e o corpo.

\section{ALGUMAS CONSIDERAÇÕES}

A análise multimodal do texto possibilita vislumbrar as formas como os modos semióticos são orquestrados na produção de significados. A exploração do potencial desses modos revela como o discurso vai se tecendo, mais especificamente sobre saúde. O design multimodal constrói significados representativos e interativos e composicionais dentro da reportagem, revelando posições sociais que explicitam um primado pela saúde e pelo corpo. As possibilidades de escolhas modais revelam o design da entidade semiótica e as indicações da percepção do produtor, o qual medeia as características do que é comunicado com as características do seu público e com os recursos que estão disponíveis. 
Assim, os propósitos semióticos do 'designer' apontam para os textos como complexos de signos na perspectiva dos arranjos/organização do mundo em movimento. $\mathrm{O}$ produtor de significados movimenta-se no mundo e o mundo ao seu redor está em constante movimento, coadunando com as postulações de Kress $(2010$, p.50) ao situar que o ambiente social muda, as práticas sociais e discursivas também mudam; em decorrência dessas mudanças, "o design da mensagem precisa mudar, pois a mudança é o motor que impulsiona a mudança semiótica, de acordo com a mudança social".

Em cada página da reportagem a escolha de cada modo cria um paralelismo entre as semioses, possibilitando uma unidade textual. A repetição de cores, o uso da tipografia e formas em diferentes elementos cria uma rima/harmonia textual além de enfatizar as informações representadas no plano verbal com a promessa do resultado descrito no plano visual, conforme demonstra a capa. Essa articulação possibilita a intersemiose entre linguagem e imagem em que modos semânticos visuais e verbais se complementam na veiculação de um discurso. Toda orquestração do fluxo semiótico reflete a distribuição das metafunções no texto. Elas, não necessariamente, estão distribuídas de forma similar em todas as modalidades semióticas. Diferentes pesos e distribuições das metafunções são apresentadas nas diferentes fases do texto, para apresentar o conteúdo e estabelecer as relações com o leitor bem como integrar o fluxo textual.

No que se refere aos elementos visuais, eles são marcados por estruturas conceituais que descrevem os participantes em relação à essência e classe. A reportagem é marcada por processos classificassionais, agrupando os participantes em categorias e os respectivos papéis que desempenham no organismo para manutenção da saúde. Em relação aos aspectos interativos, as imagens, em sua grande maioria, são enquadradas numa distância social do participante interativo, colocando-se, assim, como itens ao alcance do consumo do leitor. Contudo, alguns elementos visuais são apresentados numa distância impessoal, caracterizando-se por um item a ser contemplado dentro da gama de informações, imprimindo, assim, um caráter de maior formalidade ao texto. Há exploração dos aspectos sensoriais a partir da conjugação das cores, brilho, tamanho de determinadas imagens, principalmente, as classificadas como ideais para serem consumidas e utilizadas.

Em relação à construção dos significados ideacionais, as escolhas realizadas revelam predomínio dos processos materiais e relacionais. As escolhas dos processos materiais pontuam a dinâmica das ações dos participantes e os colocam, de maneira geral, para melhor esclarecimento do leitor, em dois polos: os que cooperam e são eficientes no equilíbrio da saúde e aqueles que se colocam como risco ou uma potencial ameaça.

A reportagem é marcada por uma negociação de significados por meio de papéis de fala de dar informações e demanda de informações e bens \& serviços. Os atos de fala de dar informações perduram nos textos, buscando objetivar uma troca de conhecimento/informações, enquanto os atos de fala de demanda, mediante perguntas, interpelam o leitor. Nesses atos de fala, há o predomínio do predicador no tempo do presente, trazendo a argumentação dos textos para o tempo do aqui e agora do leitor. Cada afirmação, pergunta e comando posicionam o leitor a reagir - por meio de reconhecimento, aceitação e questionamento. 
Os significados construídos dentro da reportagem buscam representar os participantes dentro das suas ações e características que reforçam um ideal de busca e manutenção da saúde e boa forma, a partir da troca de informação e de atividade que proscrevem e prescrevem hábitos alimentares, dietas, regularidades de atividades físicas etc. Nota-se uma preocupação de revelar informações relacionadas aos cuidados e às formas que indicam um corpo saudável. A reportagem analisada revela os movimentos das fontes semióticas na construção de representações e no estabelecimento de relações que situam (quais) prioridades do cuidado com a saúde e o corpo devem ser dadas pelos participantes interativos.

Em suma, falar do corpo é falar em linguagem, já que o corpo é também o que dele se diz.Nesse sentido, voltamos nosso olhar sobre como a noção, saúde, corpo saudável é construída multimodalmente. O corpo torna-se um local de interação, apropriação e reapropriação, ligando processos reflexivamente organizados com o conhecimento dos peritos. Nesse espaço de conhecimento, encontram-se cada vez mais livros e manuais práticos sobre saúde, dieta, aparência, exercício, fazer amor e muitas outras coisas. Pelas influências da modernidade tardia, o corpo tornou-se disponível para ser conhecido e trabalhado.

\section{REFERÊNCIAS}

DESCARDECI, M. A. A. S. Ler o mundo: um olhar através da semiótica social. ETD: Educação Temática Digital, Campinas, Unicamp, v. 3, n. 2, p. 19-26, jun. 2002.

FIGUEIREIDO, D. C. Linguagem e gênero social: contribuições da análise crítica do discurso e da linguística sistêmico-funcional. Revista Delta 25 especial, p. 732-753, out. 2009.

HALLIDAY, M.A.K. An introduction to functional grammar. London: Edward Arnold, 1985.

HALLIDAY, M.A.K; MATTHIESSEN, C. An introduction to functional grammar. $3^{\text {a }}$ ed. London: Hodder Education, 2004.

HODGE, R., KRESS, G. Social Semiotics. London: Polity Press, 1988.

KRESS, G.; VAN LEEUWEN, T. Multimodal Discourse: The modes and media of contemporary communication. London: Arnold, 2001

Reading images: the grammar of visual design. London; New York: Routledge, 1996 [2006].

MARTIN, J. R. English Text: System and Structure. Amsterdam/Philadelphia: John Benjamins, 1992.

LEMKE, J. Multimodality, identity, and time. In: JEWITT, C. (Org.). The Routledge handbook of multimodal analysis. London: Routledge, 2011.

MOTTA-ROTH, D. A popularização da ciência como prática social e discursiva. In: MOTTA-ROTH, D.; GIERING, M. E. (Org.). Discursos de popularização da ciência (Anais do Encontro do Núcleo de Estudos Avançados "Linguagem Cultura e Sociedade" - GT Labler), 2009. Santa Maria: LABLER-PPGL/UFSM, 2009a.

SABAT, R. Gênero e sexualidade para consumo. In: LOURO, G.L. et al. (Orgs.) Corpo, Gênero e sexualidade: um debate contemporâneo na educação. Petrópolis, RJ: Vozes, 2003.

SANTAELLA, L. Corpo e comunicação: sintoma de cultura. São Paulo: Paulus, 2004. O'TOOLE, M. The Language of Displayed Art. London: Leicester University Press. 
Artigo recebido em: ago. de 2019.

Aprovado e revisado em: fev. de 2020.

Publicado em: julho de 2020.

Para citar este texto:

SANTOS, Záira Bomfante dos.; COSTA, Eliane Gonçalves da. A Expansão Semântica dos Significados sob a Ótica da Semiótica Social. Entremeios [Revista de Estudos do Discurso, ISSN 2179-3514, on-line, www.entremeios.inf.br], Seção Estudos, Programa de Pós-Graduação em Ciências da Linguagem (PPGCL), Universidade do Vale do Sapucaí (UNIVÁS), Pouso Alegre (MG), vol. 21, p. 4-20, jan. - jun. 2020.

DOI: http://dx.doi.org/10.20337/ISSN2179-3514revistaENTREMEIOSvol21pagina4a20 